\title{
P 188 DECIDING RIGHT: RIGHT CARE, RIGHT PLAN, RIGHT PATIENT; AN INDIVIDUALISED APPROACH TO PALLIATIVE CARE'
}

Tun Than, ${ }^{1,4,5}$ Zahida Adam, 3,4,5 Preeti Wadhhwa, 2,4,5 Mohamed Ayubi ${ }^{2,4,5}$. ${ }^{1}$ Humberstone Medical Centre, Leicester, UK; ${ }^{2}$ Hilltop Medical Centre, Leicester, UK; ${ }^{3}$ Willowbrook Medical Centre, Leicester, UK; ${ }^{4}$ Macmillan Cancer Support, London, UK; ${ }^{5}$ NHS Leicester City Clinical Commissioning Group, Leicester, UK

10.1136/bmjspcare-2014-000654.229

Background Recognising the scope for improvement in palliative care services across Leicester city, the commissioning group, the local hospice (LOROS) and Macmillan Cancer Support collaborated in launching an innovative "Deciding Right" project. The project aims to promote identification of patients in their last year of life to provide a timely and robust multidisciplinary care based on the patient's choices.

Description The project emphasizes on training and education of local health care professionals at various levels. Four locality GP mentors, appointed to facilitate and deliver the objectives of the project, received training at masters level in conjunction with Demon Fort University. The unique collaboration of the commissioning group, local palliative care consultants and Macmillan Cancer Support paved the pathway for the appointed mentors to access training at national level through Macmillan GP support program in addition to locally provided mentoring support from the palliative care consultants. Furthermore, the project also promoted identification of a palliative care lead GP for each participating practice. All lead GPs are given training in identification of patients in their last year of life along with communication skills to conduct effective and timely discussion with the patients and families to develop and implement the mutually agreed palliative care plans in collaboration. The target group for training extended to include sessional GPs and carers from local residential homes to enable them to understand and apply core concepts of palliative care.

Results and reflections The project achieved improvements in the palliative care register across the city and paved the path to develop further through implementation of after death audits (ADA). It also highlighted the need for more comprehensive guidelines for anticipatory prescribing. Initial survey of ADA data has shown that most $(>90 \%)$ of the patients who have care plans achieved their choices including their preferred place of death. 